reactor systems. Since some 2,000 papers were presented at the 1958 Geneva Conference, of which at least 250 were directly concerned with nuclear reactors, a review of the papers on reactors would have been of greater value. It is, however, to be regretted that the present work falls below the very high standards set by earlier volumes in the series, since instead of presenting reviews of the material presented at the 1958 Conference, it contains only reprints of a selection of the papers.

Although all these papers were published in the complete Conference Proceedings three years before the present work appeared, there is some value in having in a single compact volume a selection of papers dealing with one particular field, together with an index. However, any selection of 16 papers from so many is bound to be to some extent arbitrary, resulting in undue attention to detail in some areas at the expense of inadequate general coverage. For example, more than 150 pages are devoted to British, American and Russian work on physical measurements on fast reactor experimental assemblies, but the reader must refer to the full Proceedings to appreciate the relevance of such work to the design of a fast power reactor. Similarly, on a more general level, good descriptions are given of five different types of reactor system, but the reader will look in vain for any information on the design and operating experience of the two reactor systems first used for large-scale power production-the British gas-cooled graphite type and the United States pressurized water reactor.

It is easy to see that the editor and publishers have set themselves a very difficult task, but it is doubtful if this volume will meet the needs of the large body of readers who would have expected a more critical selection or review of the papers presented at Geneva.

L. ROTHERHAM

\section{INDEX OF DIFFERENTIAL THERMAL ANALYSIS}

Scifax (regd.) Differential Thermal Analysis Data Index, with Mineral, Inorganic and Organic Sections

Compiled by Dr. R. C. Mackenzie. Comprising 1630 punched cards (20 Introductory, 1012 Mineral, 287 Inorganic, 311 Organic); and Extra Code Card, 31 Guide Cards, Two 8 in. needles with handles, and Explanatory booklet. (London: Cleaver-Hume Press, Ltd., 1962.) £55.

7 HIS index consists of punched cards which are slotted to record the temperatures and sense of the principal and second differential thermal analysis peaks and whether these occur in an inert atmosphere. To code the peak temperatures, the range from less than $-100^{\circ} \mathrm{C}$ to greater than $1,800^{\circ} \mathrm{C}$ is divided into intervals (mainly $50^{\circ} \mathrm{C}$ ) and to each is assigned a number from 1 to 27 . The numbers are recorded on the card and also slotted on the upper edge, the other three edges remaining free. Each eard is numbered and gives the name of the substance, its composition, and, if it is a mineral, a reference to Hey's Chemical Index of Minerals'. The various peaks that authors attribute to the substence, with reference to the literature as well as to other cards, are also recorded.

It is natural to compare the 'Scifax' index with the well-known X-ray powder data card file (by A.S.T.M.).
The A.S.T.M. file is available in several versions, including punched cards (but not slotted). The cards give the three principal $d$ spacings and their relative intensities as well as the complete powder pattern of the substance and, if available, the experimental conditions, cell constants, system, space group, optical data and references. In comparison, the 'Scifax' cards record only the bare minimum of information; obviously they would be more useful if the evidence of the purity of the listed samples, nature of the reactions occurring at differential thermal analysis peaks and experimental conditions were also shown. The A.S.T.M. file distinguishes data of high reliability, and this could with profit be followed in the 'Scifax' index because there is unnecessary duplication of cards, and the proportion of questionable minerals is too high. The fault is more noticeable among the clay minerals where about 10 per cent are dubious (for example, monothermite, polynite, serpentine, hydrogoethite, beidellite, gumbrin, iron-magnesian parahalloysite, etc.).

The method of sorting cards is reasonably satisfactory, and it is usually possible to find cards from their coding without much ambiguity. The 'Scifax' index is arranged alphabetically, but the compiler suggests resorting the cards either according to their coding (for diagnosis) or according to their chemical composition (for reference). For diagnosis, it would be necessary to code and slot two more edges with the substance reference number so as to be able to retrieve cards.

While the inorganic section consists in the main of data of well-defined compounds and is a welcome addition to the literature, the organic section includes a noticeable proportion of cards of poorly defined high-molecular weight compounds (for example, calcium resinate, humic acid, albumen, 'Amberlite' resin, fibrin, carbolignin, etc.). If a work of reference must record data of poorly defined materials it is better that they are put into a separate section.

The 'Scifax' index is well produced and if used with caution it could be useful in identification, but its chief value lies in being a convenient source of information, especially if the data are supplemented by the user.

R. GREENE-KELLY

${ }^{1} \mathrm{Hey}, \mathrm{M}$. H., An Index of Mineral Species and Varieties (British Museum (Natural History ), Iondon, 1950).

\section{RECENT DEVELOPMENTS IN HIGH- PRESSURE TECHNIQUES}

\section{Modern Very High Pressure Techniques}

Edited by Dr. R. H. Wentorf, Jr. Pp. xiv +233. (London: Butterworth and Co. (Publishers), Ltd., 1962.) 608 .

T $\mathbf{T}$ is eighty-two years ago that J. R. Hannay probably first produced artificial diamonds by the application of high pressure and temperature. Since that period the interest in high pressure has increased enormously because of the fundamental importance of the properties of matter under the extremes of pressure and temperature, and the possibilities of permanently modifying the structure of common materials.

The practical difficulty of research in this field has always been the design and the materials of construction of the containing vessel and plunger. Bridgman made the first major step forward from 